\title{
Zinc induces caspase-dependent mitochondrial pathway of the programmed cell death in haemocytes of Drosophila melanogaster
}

\author{
Marta Filipiak • Grzegorz Tylko • Elzbieta Pyza
}

Received: 13 January 2012/ Accepted: 9 February 2012/Published online: 25 February 2012

(C) The Author(s) 2012. This article is published with open access at Springerlink.com

\begin{abstract}
Zinc is an essential trace element in cells. However, its high level in cytoplasm promotes activation of stress signaling pathways and may lead to cell death. In the present study we used Drosophila melanogaster blood cells (haemocytes), obtained from the third instar larvae, to study the effects of high concentrations of $\mathrm{Zn}^{2+}$ on programmed cell death (PCD). We analyzed the activity of caspases, the level of caspase inhibitor protein DIAP1 and metallothioneins, as well as calcium concentrations and activity of mitochondria in haemocytes exposed to 0.35 and $1.7 \mathrm{mM}$ concentrations of $\mathrm{Zn}$. The obtained results showed that rapid increase of $\left[\mathrm{Zn}^{2+}\right]_{i}$ in the cytoplasm up-regulates metallothionein $M t n B$ but not MtnA gene expression in cells treated with $\mathrm{Zn}^{2+}$ in both concentrations. Excess of $\mathrm{Zn}^{2+}$ also induced activation of the initiator caspase Dronc, associated with the mitochondrial pathway of PCD, and the effector caspase DrICE. In turn, the activity of receptor-regulated Dredd caspase was not changed. The level of DIAP1 decreased significantly in haemocytes in the presence of high $\mathrm{Zn}^{2+}$ concentration in comparison to untreated cells. Moreover, mitochondrial membrane potential was significantly decreased after exposure to $\mathrm{Zn}$ ions. These results indicate that high concentration of $\mathrm{Zn}^{2+}$
\end{abstract}

M. Filipiak · G. Tylko · E. Pyza ( $\square)$

Department of Cell Biology and Imaging, Institute

of Zoology, Jagiellonian University, Gronostajowa 9,

30-387 Kraków, Poland

e-mail: elzbieta.pyza@uj.edu.pl in the cytoplasm of haemocytes induces PCD via a mitochondrial pathway and that caspases play a pivotal role in this process.

Keywords Apoptosis - Metallothioneins · Mitochondria · Haemolymph · Fruit fly

\section{Introduction}

Divalent zinc cations $\left(\mathrm{Zn}^{2+}\right)$ are present in all living organisms and are important in development and metabolism of cells. $\mathrm{Zn}^{2+}$ is a cofactor of more than 300 enzymes and a structural component of thousands of transcription factors (John et al. 2010). Zinc acts as a second messenger or a neurotransmitter, participating in gene expression, DNA/protein synthesis and in extracellular signal transduction. Thus, it is involved in cell growth, differentiation, proliferation and especially, in cell survival or death (Wellinghausen et al. 1997; Rink and Gabriel 2000; Bayersmann and Haase 2001).

The physiological concentration of $\mathrm{Zn}$ ions is controlled by endogenous mechanisms and differs depending on cell type. The mechanisms that regulate the intracellular $\mathrm{Zn}^{2+}$ level are very complex and generally based on zinc interactions with specific cytoplasmic proteins, e.g., metallothioneins (MTs). In result, the free cytoplasmic fraction of $\left[\mathrm{Zn}^{2+}\right]_{i}$ is maintained at a low level (Tubek 2007; Lichten and Cousins 2009). Although Zn ions are usually thought 
as being relatively harmless, any fluctuations of $\left[\mathrm{Zn}^{2+}\right]_{i}$ affect cell activity and promote cell death (Truong-Tran et al. 2000). Especially, cells of the immune system are sensitive to changes in $\mathrm{Zn}$ ion concentration. Deficiency of $\mathrm{Zn}^{2+}$ results in increased susceptibility of immune cells to pathogens and in a consequence, leads to immune disorders like lymphopenia or thymus atrophy (Fraker et al. 2000). Even a mild decrease in $\mathrm{Zn}^{2+}$ concentration depresses the activity of immune cells. For example, cytotoxicity of NK cells is significantly impaired, phagocytotic activity of macrophages and neutrophils is reduced, $\mathrm{B}$ cells show apoptotic features whereas $\mathrm{T}$ cells are stimulated to auto- and alloreactivity (Ibs and Rink 2003).

In cell survival or death decisions, $\mathrm{Zn}^{2+}$ plays a dual role. This role depends on both cell-specificity and metal concentration in the extracellular space and in the cytoplasm. It has been reported that low concentrations of $\mathrm{Zn}$ ions in the cell environment suppress apoptosis in many cell types stimulated to enter programmed cell death (PCD) pathways (Flieger et al. 1989; Fraker and Telford 1997; Perry et al. 1997; Aiuchi et al. 1998; Neves et al. 1998; Ze-peng et al. 2005). On the other hand, high concentrations of $\mathrm{Zn}^{2+}$ might induce PCD, the effects normally observed in $\mathrm{Zn}$-deficiency. Proapoptotic activity of $\mathrm{Zn}^{2+}$ has been observed in different cell types either as a consequence of exogenous administration of $\mathrm{Zn}$ ions or after their release from cytoplasmic stores (Zhang et al. 2004; Knoch et al. 2008). It has also been reported that $\mathrm{Zn}^{2+}$ highly interacts with DNA, decreases mitochondrial membrane potential, impairs the stability of lysosomes, and inhibits proteins from IAP family. These events are sufficient to induce PCD (Sensi et al. 2003; Lee et al. 2009; Ku et al. 2010; Rudolf and Červinka 2010).

Haemocytes of Drosophila melanogaster take part in immune responses. They circulate in the haemolymph and their main role is the elimination of pathogens and parasites. In D. melanogaster, haemocytes are divided into three types: plasmatocytes, crystal cells and lamellocytes. The most numerous cells are plasmatocytes that functionally resemble mammalian macrophages. These cells participate in phagocytosis and production of antimicrobial peptides. Crystal cells possess crystalline cytoplasmic inclusions that contain phenoloxidase, necessary for melanization and wound repair. The lamellocytes are only present in larvae and appear after infection of larvae with parasites (Hoffman 1995; Echalier 1997; Lavine and Strand 2002; Meister 2004). Generally, the studies on D. melanogaster haemolymph cells, obtained from healthy larvae, are based on plasmatocytes. Lamellocytes are very rare whereas crystal cells degenerate within a few minutes after haemolymph collection (Ribeiro and Brehélin 2006).

Programmed cell death pathways in D. melanogaster and mammalian cells have the same core components (Abrams 1999). The major cysteine protease in D. melanogaster is the initiator caspase Dronc (homologue of the mammalian caspase-9) that is autoactivated in a protein complex called apoptosome (Dorstyn et al. 1999). Another caspase, DrICE, the mammalian caspase-3 homologue, is responsible for massive substrate cleavage and cell degradation (Song et al. 2000). In turn, Dredd is a homologue of mammalian initiator caspase- 8 and it probably takes part in receptor-mediated PCD. However, it has been suggested that immune responses of cells require Dredd activity (Siegel 2006). The regulation of D. melanogaster caspase activity is under control of IAP proteins: DIAP1, DIAP2 and Deterin but only DIAP1 inhibits all death enzymes (Richardson and Kumar 2002).

As we have already reported (Szczerbina et al. 2008; Filipiak et al. 2010; Borowska and Pyza 2011), haemocytes isolated from wandering larvae of the third larval instar represent an excellent model to study the impact of many substances on cell-dependent immune responses. We have found that PCD of haemocytes is enhanced in the presence of high concentrations: 0.35 and $1.7 \mathrm{mM}$, of $\mathrm{Zn}$ ions. In our earlier study, we have observed that proapoptotic activity of $\mathrm{Zn}^{2+}$, revealed by phosphatidylserine exposure in the external leaflet of the cell membrane, is independent on caspase activity but we have studied total activity of either initiator and effector caspases using pan-caspase detection system.

The aim of the present study was to investigate $\mathrm{Zn}^{2+}$ content in haemocyte cytoplasm after exposure of cells to 0.35 and $1.7 \mathrm{mM} \mathrm{Zn^{2+ }}$ and effects of both concentrations on: metallothionein gene expression (MtnA and MtnB), activity of caspases Dredd, Dronc and DrICE, the level of caspase inhibitor DIAP1, mitochondrial membrane potential, and on $\mathrm{Ca}^{2+}$ concentration in haemocytes. 


\section{Materials and methods}

Animals

Adult fruit flies (D. melanogaster), Canton S, were obtained from the laboratory stock, kept in plastic flasks of $0.175 \mathrm{dm}^{3}$ volume and fed with a standard cornmeal medium. Fruit flies were maintained at a constant temperature $\left(24 \pm 1^{\circ} \mathrm{C}\right)$ and in a light:dark cycle (LD 12:12). Females laid eggs in the feeding medium for $24 \mathrm{~h}$ and then adults were removed. Larvae were reared until the wandering stage in the third larval instar.

Haemocytes isolation and $\mathrm{Zn}$ exposure

The third instar larvae of D. melanogaster were thoroughly washed in Hank's Balanced Salt Solution (HBSS), pH 7.2, decapitated individually with a springbow dissecting microscissors and $20 \mu \mathrm{l}$ of haemolymph was collected with a glass capillary (Microcaps, Drummand Scientific, USA). To maintain the number of haemocytes at $4 \times 10^{6}$ per $1 \mathrm{ml}, 20 \mu \mathrm{l}$ of haemolymph was suspended in $280 \mu \mathrm{l}$ of calcium free HBSS, pH 7.2. The number of haemocytes in diluted samples was established on the basis of several measurements by means of flow cytometry. The cell suspension was finally divided into four groups: (1) exposed to $0.35 \mathrm{mM}$ of $\mathrm{Zn}^{2+}$, (2) exposed to $1.7 \mathrm{mM}$ of $\mathrm{Zn}^{2+}$, (3) control without $\mathrm{Zn}^{2+}$ exposure, (4) positive or negative controls depending on the experiment. Before the treatments, cells were isolated from larval haemolymph by centrifugation at $1,500 \times g$ for $15 \mathrm{~min}$. Zinc ion solutions used in the study were prepared from $\mathrm{ZnCl}_{2}$ (Merck, Germany). Finally, haemocytes were incubated for $3 \mathrm{~h}$ at $22^{\circ} \mathrm{C}$ in darkness, while slowly shaken in Rotomix 50800 (Thermolyne, USA).

Measurements of intracellular $\mathrm{Zn}^{2+}$ concentration

Evaluation of $\left[\mathrm{Zn}^{2+}\right]_{i}$ in haemocytes was performed using a fluorescent indicator FluoZin ${ }^{\mathrm{TM}}-3$, AM ester (Molecular Probes, USA) and analyzing images obtained with a confocal microscope (Zeiss LSM 510 META, Zeiss, Germany). Haemocytes suspended in the Schneider's medium were placed onto glass microscope coverslips and allowed to adhere to the glass surface for about $1 \mathrm{~h}$. Then, cells were treated with two concentrations of $\mathrm{Zn}$ ions in HBSS for $3 \mathrm{~h}$. After that, an excess of $\mathrm{Zn}^{2+}$ was removed by washing the cells with HBSS and haemocytes were loaded with $5 \mu \mathrm{M}$ solution of FluoZin-3 in HBSS, and incubated in darkness for $30 \mathrm{~min}$. After loading, haemocytes were washed with HBSS and fluorescent images were taken with the confocal microscope. Fluorescence intensity of individual cells was measured using LSM-FCS software (Zeiss, Germany) and $\left[\mathrm{Zn}^{2+}\right]_{i}$ was calculated from the mean fluorescence intensity of cells according to the formula: $\left[\mathrm{Zn}^{2+}\right]_{i}=\mathrm{K}_{\mathrm{d}} \times\left[\left(\mathrm{F}-\mathrm{F}_{\min }\right) /\left(\mathrm{F}_{\max }-\mathrm{F}\right)\right]$, where FluoZin-3 $\mathrm{K}_{\mathrm{d}}\left(\mathrm{Zn}^{2+}\right)=15 \mathrm{nM}$. Maximal $\left(\mathrm{F}_{\max }\right)$ and minimal $\left(\mathrm{F}_{\mathrm{min}}\right)$ values of FluoZin-3 fluorescence were estimated for the cells treated with $100 \mu \mathrm{M}$ solution of zinc ionophore-pyrithione (2-mercaptopyridine-1-oxide sodium salt, Sigma-Aldrich, Germany) in HBSS in the presence of $2 \mathrm{mM} \mathrm{Zn}^{2+}$ and $100 \mu \mathrm{M}$ solution of zinc chelator TPEN (tetrakis-(2pyridylmethyl)-ethylenediamine, Molecular Probes, USA), respectively (Haase et al. 2006).

Real time PCR analysis of $M t n A$ and $M t n B$ gene expressions

The concentration of RNA in Zn-treated and control group of haemocytes was assessed using a spectrophotometer (NanoDropMolecular Probes, $\mathrm{USA}^{\mathrm{TM}_{2}} 2000$, ThermoSCIENTIFIC, USA) after treatment of cells with Trizol Reagent (Invitrogen, USA), according to the manufacturer's protocol. Total RNA $(1 \mu \mathrm{g})$ was converted into cDNA by means of reverse transcription system containing oligo(dT) and SuperScriptIII FirstStrand Synthesis System for RT-PCR (Invitrogen, USA) in $20 \mu$ reaction volume. The Real Time PCR amplification was performed with a Step One Plus System (Applied Biosystems, USA) using the mixture of diluted cDNA template ( $5 \mu 1,1: 3$ solution of nuclease free water), Power SYBR Green Master Mix (Applied Biosystems, USA), and gene-specific primers. The primers: $M t n A, M t n B$ and rpl32 (Ribosomal Protein L32) were designed using Primer-BLAST software (NCBI, USA) and synthesized at GenoMed (Poland). The following $D$. melanogaster primer sequences were utilized: metallothionein A, forward, 5'-TGCGGAAGC GGTAAGTTCGCAG-3', reverse, 5'-ATTTCTTGTC GCCGCCGCACT-3' (product length: $352 \mathrm{bp}$ ), metallothionein $\mathrm{B}$, forward, 5'-GCCTCAGCCAAGTGA AAGTCGAGA-3', reverse, 5'-ACAGCTTGCTGCT GCGTTGT-3' (product length: 94 bp), and Ribosomal 
Protein L32, forward, 5'-AGAAGCGCAAGGAGAT TGTC-3', reverse, 5'-ATGGTGCTGCTATCCCAAT C-3' (product length: 233 bp). Changes in metallothionein gene expressions in $\mathrm{Zn}$-treated haemocytes in relation to the control group were based on the $\Delta \Delta C_{\mathrm{T}}$ method (Livak and Schmittgen 2001) in the presence of normalizing rpl32 gene.

Estimation of caspase Dredd, Dronc and DrICE activity

The activities of selected $D$. melanogaster caspases were measured in haemocytes using Caspase-Glo 3/7 Assay for caspase DrICE, Caspase-Glo 9 Assay for caspase Dronc and Caspase-Glo 8 Assay (Promega, USA) for caspase Dredd. As the positive control in this experiment, the fruit fly's haemocytes were treated with $1 \mu \mathrm{M}$ staurosporine (Sigma-Aldrich, Germany) for $3 \mathrm{~h}$. Next, the control group of cells and groups treated with $\mathrm{Zn}$ were lysed for $30 \mathrm{~min}$ at $4^{\circ} \mathrm{C}$ with a buffer containing Tris-HCl, pH 7.5 (20 mM, Merck, Germany), sodium chloride (150 mM, Chempur, Poland), $\mathrm{Na}_{2}$ EDTA (1 mM, POCH, Poland), EGTA (1 mM, Sigma, Germany), 1\% Triton X-100 (Calbiochem, USA), sodium pyrophosphate $(2.5 \mathrm{mM})$, $\beta$-glycerophosphate $(1 \mathrm{mM})$. Then, the samples were centrifuged at $1,500 \times g$ for $15 \mathrm{~min}$ at $4^{\circ} \mathrm{C}$, supernatant was collected and protein content was estimated using Micro BCA Protein Kit (Thermo Scientific, USA). The solutions with $30 \mu \mathrm{g}$ of protein were prepared and mixed with appropriate caspase reagent in 1:1 ratio, according to the manufacturer's protocol. After $1 \mathrm{~h}$ of incubation at room temperature in darkness, luminescence of the samples was measured using a luminometer (GloMax ${ }^{\circledR}$ 20/20 Single Tube Luminometer, Promega, USA).

Determination of DIAP1 protein level by immunocytochemistry

$100 \mu \mathrm{l}$ of haemocyte suspensions from both control groups and $\mathrm{Zn}$-treated ones were dropped onto glass coverslips and left to adhere for $1 \mathrm{~h}$. Then all experimental groups were fixed with $2 \%$ formaldehyde solution in phosphate buffer (PBS) $(\mathrm{pH}$ 7.4) for $10 \mathrm{~min}$ at room temperature. Fixed specimens were thoroughly washed with PBS and additionally permeabilized with $0.1 \%$ Triton X-100 in PBS for 5 min. Next, 3\% BSA in PBS was used to block unspecific antibody binding for $30 \mathrm{~min}$ and immunolabeled overnight at $4^{\circ} \mathrm{C}$ with the mouse primary monoclonal antibodies against DIAP1 (Abcam, USA), diluted $1: 1,000$ in $3 \%$ BSA solution in PBS. The excess of antibodies was removed by washing with PBS and then the haemocytes were incubated with $3 \%$ BSA in PBS for $30 \mathrm{~min}$. The secondary goat anti-mouse antibodies $\mathrm{Cy}^{\mathrm{TM}} 3$-conjugated (Jackson ImmunoResearch, USA) were finally used to label DIAP1 protein. The specimens were rinsed with PBS before mounting with Vectashield Mounting Medium for Fluorescence (Vector Laboratories Inc., USA). Confocal images were taken and the fluorescence intensity of individual cells was measured using LSM-FCS software.

Measurements of mitochondrial membrane potential $\Psi_{\mathrm{m}}$

To estimate mitochondrial membrane potential $\Psi_{\mathrm{m}}$ in control and Zn-treated haemocytes, MitoProbe ${ }^{\mathrm{TM}} \mathrm{JC}-1$ Assay Kit was used (Molecular Probes, USA). JC-1 (5,59,6,69-tetrachloro-1,19,3,39-tetraethylbenzimidazolcarbocyanine iodide) is a potentiometric mitochondrial fluorochrome that aggregates in intact and negatively charged mitochondria emitting red fluorescence, whereas in cells with depolarized mitochondria, $\mathrm{JC}-1$ is present in a form of cytoplasmic monomer showing green fluorescence. All experimental groups of haemocytes were pelleted at $1,500 \times \mathrm{g}$ for $15 \mathrm{~min}$ at $22^{\circ} \mathrm{C}$ and suspended in $2 \mu \mathrm{M}$ solution of JC- 1 dissolved in HBSS. The cells were stained for $30 \mathrm{~min}$ in darkness, centrifuged, resuspended in HBSS, and transferred into 96-well plates. As the positive control, cells stained with JC-1 indicator were additionally treated with $0.5 \mathrm{mM}$ of CCCP (HBSS solution) that disrupts mitochondrial membrane potential. The fluorescence intensity of JC-1 aggregates was measured with a fluorimeter (GloMax ${ }^{\circledR}$-Multi Microplate Multimode Reader, Promega, USA). The collected data were normalized to the control ( $\mathrm{Zn}$-untreated) group of cells.

Determination of cytoplasmic calcium level

A calcium indicator Oregon Green ${ }^{\circledR} 488$ BAPTA-1, AM (O6807, Molecular Probes, USA) was used to estimate changes in $\left[\mathrm{Ca}^{2+}\right]_{i}$ in Zn-treated haemocytes and in the control ones. The cells were loaded with $10 \mu \mathrm{M}$ solution of Oregon Green in HBSS for $30 \mathrm{~min}$ in darkness followed by propidium iodide staining 
(20 $\mu \mathrm{g} / \mathrm{ml}, 2$ min, BD Bioscience Pharmigen, USA) to distinguish between necrotic cells/cell debris and healthy cells. Haemocyte suspensions, $100 \mu \mathrm{l}$ each, were transferred to cytometric tubes (BD Falcon ${ }^{\mathrm{TM}}$, USA), filled up to $600 \mu \mathrm{l}$ with HBSS and the fluorescence of Oregon Green intensity was measured by means of a flow cytometer (FACSCalibur, BD Instruments, Franklin Lakes, NJ USA). The obtained data were analyzed using Cell Quest (BD, USA) and WinMDI 2.8 softwares (Gregori et al. 2004).

\section{Statistical analysis}

Statistical analysis of data was performed using the Shapiro-Wilk W test for normality and the ANOVA or the non-parametric Kruskall-Wallis test (one-way test) followed by the Duncan post hoc test at $p=0.05$. Additionally, outliers were detected and removed from the dataset on the basis of the Grubb's test at $p=0.05$. All data were plotted as mean \pm SE.

\section{Results}

Intracellular $\mathrm{Zn}^{2+}$ concentration

The analysis of FluoZin-3 fluorescence intensity in haemocytes, from the third instar larvae of D. melanogaster treated with $\mathrm{Zn}^{2+}$, revealed significantly higher concentration of $\mathrm{Zn}$ ions in the cytoplasm when compared with the control, the cells non-exposed to $\mathrm{Zn}^{2+}$ (Fig. 1). The average $\left[\mathrm{Zn}^{2+}\right]_{i}$ in the control haemocytes was $3.85 \mathrm{nM}$, whereas in cells exposed to 0.35 and $1.7 \mathrm{mM}$ of $\mathrm{Zn}^{2+}$ the concentration was 23.52 and $25.63 \mathrm{nM}$, respectively.

\section{Expression of $M \operatorname{tn} A$ and $M \operatorname{tn} B$}

Real Time PCR quantification of D. melanogaster metallothionein A gene expression in larval haemocytes did not show any significant differences between control (untreated) and Zn-treated cells. On the other
Fig. 1 Representative confocal images obtained from haemocytes loaded with zinc-specific fluorochrome FluoZin-3 $\mathrm{AM}$, not exposed to $\mathrm{Zn}$ ions (control) and treated for $3 \mathrm{~h}$ with 0.35 , and $1.7 \mathrm{mM}$ of $\mathrm{Zn}^{2+}$. The histogram represents the average values $( \pm \mathrm{SE})$ of free $\mathrm{Zn}$ ion concentrations $(\mathrm{nM})$ in the fruit fly's haemocytes calculated on the basis of fluorescence intensity of FluoZin-3. **Statistically significant differences between experimental groups and control $(p<0.01, N=3)$
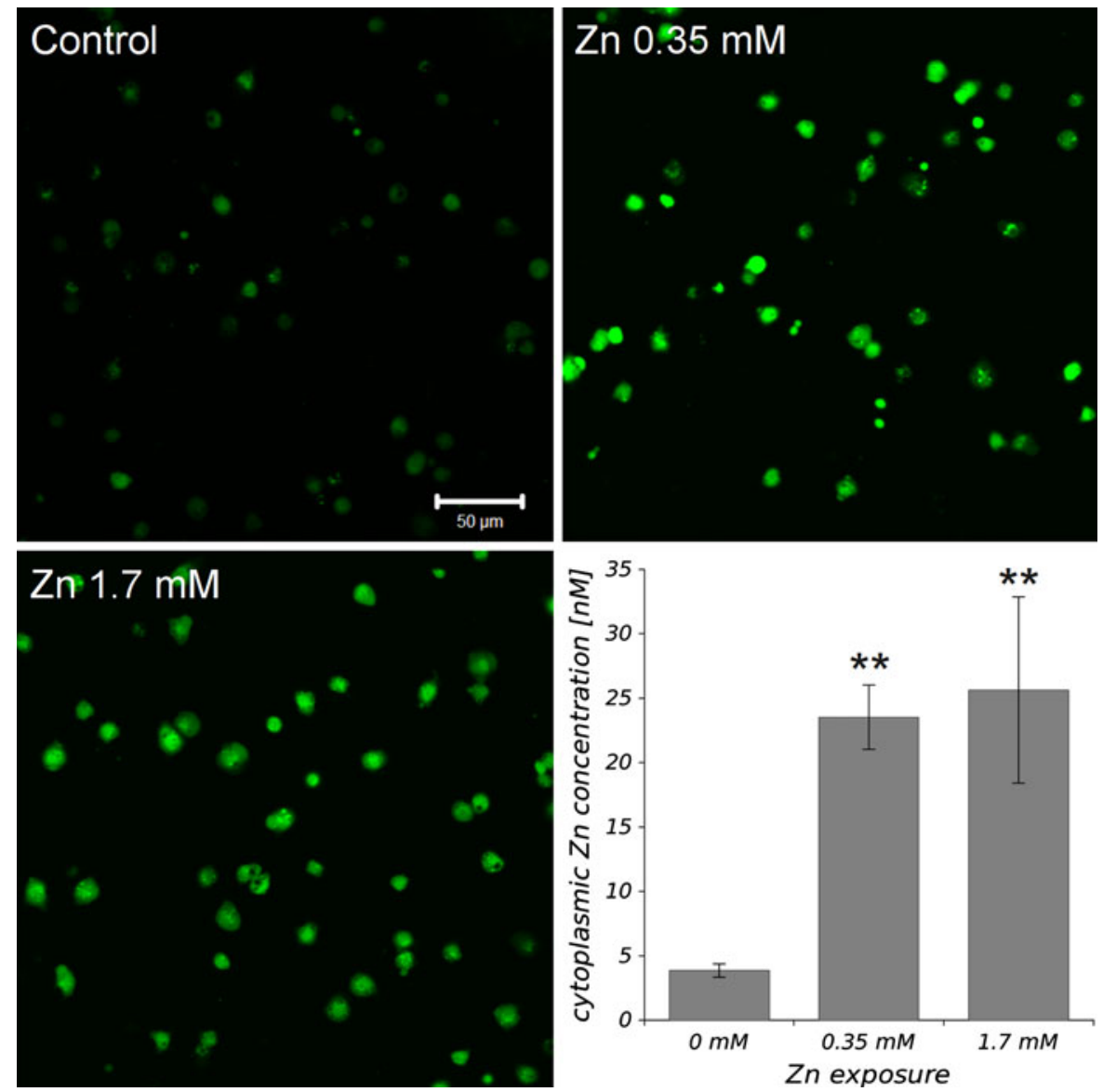
hand, both concentrations of $\mathrm{Zn}$ used in the study significantly enhanced metallothionein B gene expression. Relative quantity of the $M t n B$ mRNA revealed that haemocytes from both experimental groups $(0.35$ and $1.7 \mathrm{mM}$ ) had nearly threefold higher $M t n B$ expression than the control (Fig. 2).

\section{Activity of caspases and the level of DIAP1 protein}

The activities of caspases Dronc and DrICE in larval haemocytes of $D$. melanogaster were significantly higher in Zn-treated cells in comparison with the control (Fig. 3). The activity of Dronc increased threefold and over fourfold after treatment with 0.35 and $1.7 \mathrm{mM}$ of $\mathrm{Zn}^{2+}$, respectively. The increase of activity of the effector caspase DrICE was dependent on $\mathrm{Zn}^{2+}$ concentration. We observed fourfold and sevenfold increase of DrICE activity in comparison with the control in media containing 0.35 and $1.7 \mathrm{mM}$ of $\mathrm{Zn}^{2+}$, respectively. In contrast, any changes in the activity of Dredd were observed after applying both concentrations of $\mathrm{Zn}$ (Fig. 3). The examination of the caspase inhibitor DIAP1 in haemocytes showed that both zinc concentrations present in the cell environment significantly decrease the level of DIAP1. Two

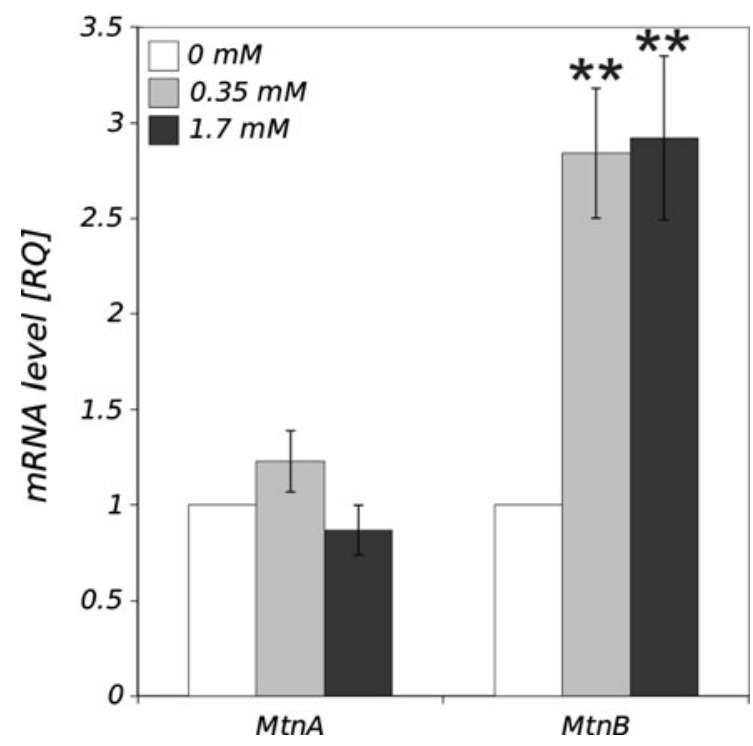

Fig. 2 The effect of $\mathrm{Zn}$ treatment $(0.35$ and $1.7 \mathrm{mM})$ on D. melanogaster MtnA and $M t n B$ gene expression in larval haemocytes quantified as mRNA levels using real-time PCR. Data are shown as RQ index calculated from $\Delta \Delta C_{\mathrm{T}}$ method (mean $\pm \mathrm{SE}$ ) normalized to the control. **Statistically significant differences between experimental groups and control $(p<0.01, N=6)$

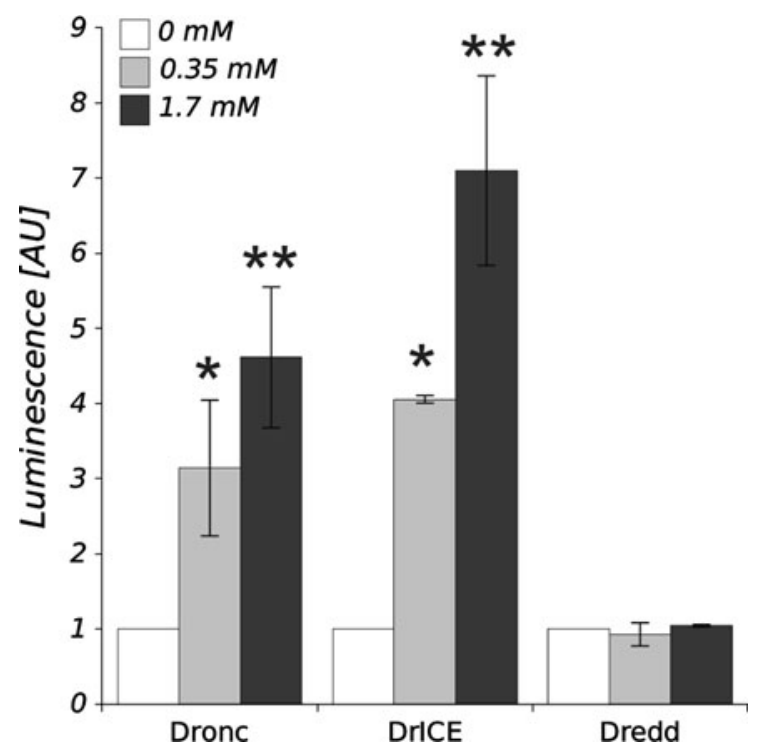

Fig. 3 The activity of caspases DrICE, Dronc and Dredd in $D$. melanogaster haemocytes in the presence of 0.35 and $1.7 \mathrm{mM}$ of $\mathrm{Zn}$ ions in comparison to the control. The results (means \pm SE) are normalized to the level of caspase activity measured in the control cells. * and **Statistically significant differences between experimental groups and control for $p<0.05$ and $p<0.01$, respectively $(N=3)$

concentrations tested, 0.35 and $1.7 \mathrm{mM}$ of $\mathrm{Zn}^{2+}$ reduced DIAP1 level by 58 and $41 \%$, respectively when compared with the control (Fig. 4).

Mitochondrial membrane potential $\Psi_{\mathrm{m}}$

Monitoring changes in the mitochondrial membrane potential using JC-1 indicator, we found statistically significant decrease of $\Psi_{\mathrm{m}}$ only in cells exposed to $1.7 \mathrm{mM}$ of $\mathrm{Zn}^{2+}$ (Fig. 5).

Intracellular $\mathrm{Ca}^{2+}$ concentration

To evaluate the effect of $\mathrm{Zn}^{2+}$ on release of $\mathrm{Ca}^{2+}$ from cellular calcium stores, $\left[\mathrm{Ca}^{2+}\right]_{i}$ concentration was measured with Oregon Green indicator by means of flow cytometry. However, no changes were observed in both $\mathrm{Zn}$-treated groups of haemocytes in comparison with the control.

\section{Discussion}

In the present study we found that $\mathrm{Zn}$ ions influence PCD in haemocytes obtained from the third instar 
Fig. 4 The results of DIAP1 expression measurements in D. melanogaster haemocytes treated for $3 \mathrm{~h}$ with 0.35 and $1.7 \mathrm{mM}$ of zinc ions and in the control, Zn-untreated cells.

Representative confocal images obtained from experimental and control groups of haemocytes. The intensity of red fluorescence exhibits the level of DIAP1 protein present in haemocyte cytoplasm. All micrographs were taken at the same imaging parameters using C-Apochromat $40 \times / 1.2 \mathrm{~W}$ corr objective. The histogram represents mean values $( \pm \mathrm{SE})$ of $\mathrm{Cy}-3$ fluorescence bound to DIAP1 proteins after immunolabelling with antiDIAP1 serum (see

"Materials and methods") in the fruit fly's haemocytes. **Statistically significant differences between experimental groups and control $(p<0.01, N=3)$
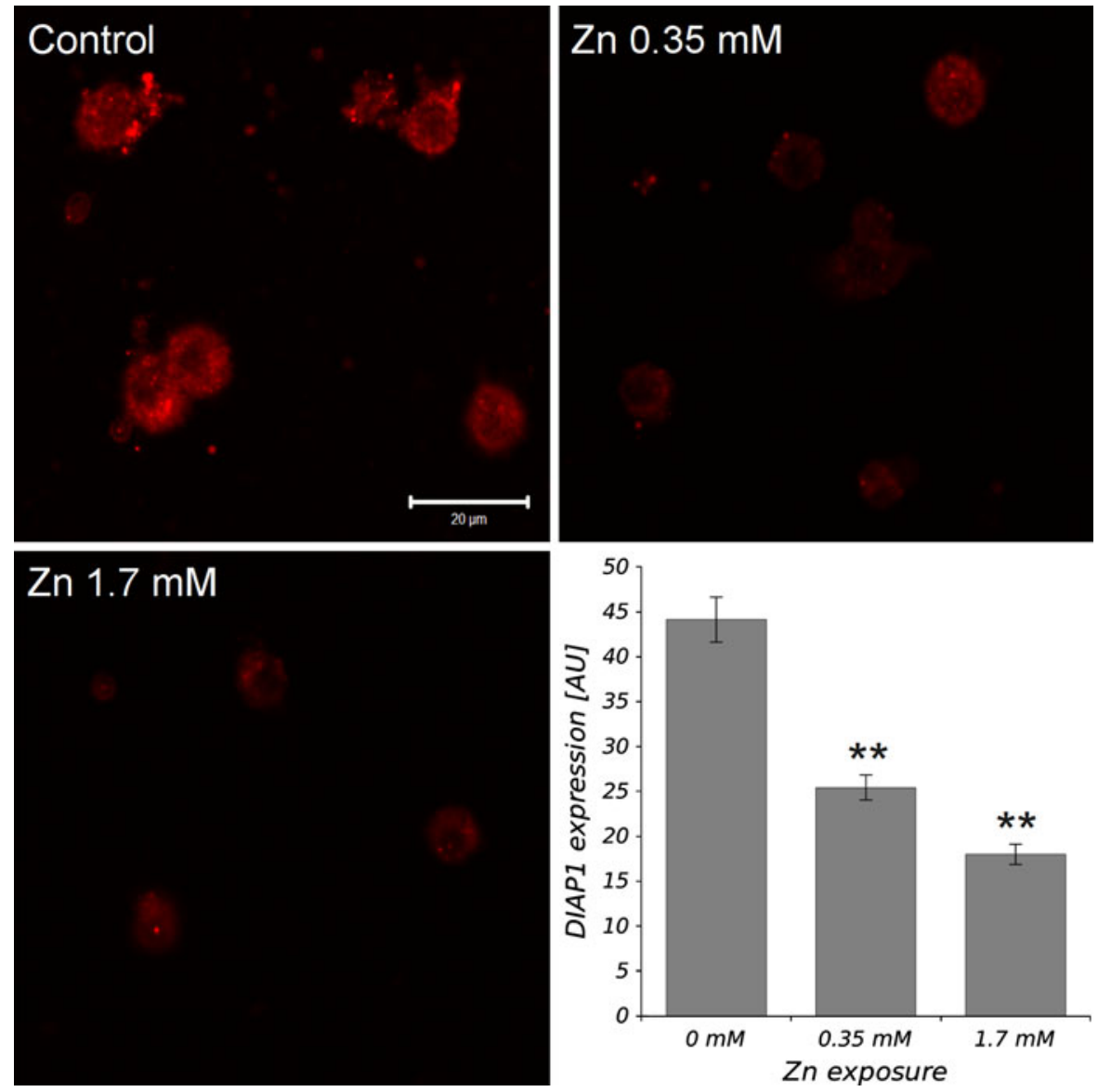

larvae of $D$. melanogaster. We treated the cells with $\mathrm{Zn}^{2+}$ in concentrations of 0.35 and $1.7 \mathrm{mM}$, since in our previous study we observed that both concentrations efficiently affect PCD in haemocytes and do not have necrotic effects on those cells (Filipiak et al. 2010). The application of $\mathrm{ZnCl}_{2}$ to the cell media resulted in rapid increase of intracellular level of free $\mathrm{Zn}$ ions, visualized with a specific free-zinc indicator FluoZin-3. The average concentration of $\left[\mathrm{Zn}^{2+}\right]_{i}$ in haemocyte cytoplasm increased about sixfold in both concentration used (Fig. 1). It indicates that $\mathrm{Zn}$ ions are easily transported to cell and increase the pool of labile $\mathrm{Zn}^{2+}$ in the cytoplasm. This labile pool of $\mathrm{Zn}^{2+}$ participates in many cellular processes and $\left[\mathrm{Zn}^{2+}\right]_{i}$ is under control of regulatory mechanisms. However, a dramatic increase or decrease of labile $\mathrm{Zn}$ ions may lead to pathological processes or cell death (Truong-Tran et al. 2000).

In D. melanogaster dMTF-1, like its mammalian counterpart MTF-1, regulates transcription of metallothioneins responsible for binding and sequestering metal ions during heavy metal stress (Balamurugan et al. 2004). Five members of the metallothionein family have already been identified in the fruit fly cells; MtnA, MtnB, MtnC, MtnD and MtnE (Atanesyan et al. 2011). Two of them, MtnA and MtnB are related to the metal metabolism but unlike in mammals, they play a minor role in cell protection during zinc toxicity. They rather bind other metals, especially copper, since they are classified as copper-thioneins (Egli et al. 2006). Zhang et al. (2001) have observed that dMTF-1 does not induce metallothionein transcription in D. melanogaster cells at the concentration of zinc that stimulates its production in mammalian cells. However, at high levels of $\mathrm{Zn}^{2+}(2 \mathrm{mM})$ that is lethal to mammalian cells, dMTF-1 stimulates metallothionein expression in D. melanogaster. Our results showed that MtnB expression increases, whereas MtnA mRNA level does not change (Fig. 2). It confirms the observations of other authors that the 


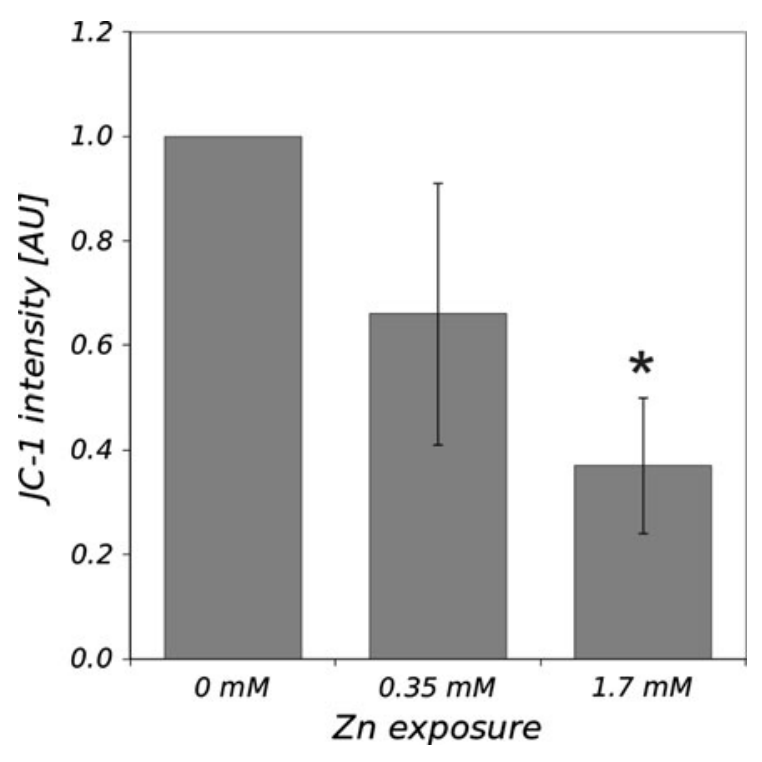

Fig. 5 Changes in mitochondrial membrane potential in D. melanogaster haemocytes after their treatment with $\mathrm{Zn}$ ions. Haemocytes were stained with JC-1 indicator and intensity of red fluorescence was analyzed fluorometrically. Living haemocytes showed strong accumulation of JC-1 indicating intact mitochondria. After zinc treatment, disruption of mitochondrial membrane potential was observed leading to the significant decrease of JC-1 red fluorescence intensity. Data were normalized to the control samples and are shown as mean \pm SE. Asterisk indicates statistically significant differences between experimental and control samples $(p<0.05, N=3)$

expression of MtnA increases in response to copper and MtnB in the presence of high concentrations of zinc or cadmium intoxication (Yepiskoposyan et al. 2006).

Our study demonstrates for the first time that D. melanogaster haemocytes utilize the caspase cascade to eliminate cells intoxicated with high concentration of $\mathrm{Zn}$ ions. The activity of caspase Dronc, the fruit fly counterpart of caspase-9, and the major effector caspase DrICE were significantly increased in zinc-treated cells (Fig. 3). It seems that the presence of active form of Dronc caspase promotes DrICE to proteolytic activity. Similarly, mammalian thymocytes show zinc-induced PCD in result of apoptosome formation and caspase- 9 activation, followed by procaspase-3 cleavage to active form of caspase-3 (Mann and Fraker 2005).

The obtained results also support the hypothesis that Dredd activity is not required for PCD in D. melanogaster cells (Fig. 3). The exposure of haemocytes to zinc ions did not activate Dredd proteins, thus receptor-mediated cell death in the fruit fly seems to play a minor role in response to zinc as it has been found in mammalian cells. Moreover, it is known that receptor-mediated PCD pathway does not involve Relish inhibition-the fruit fly's member of $\mathrm{NF} \kappa \mathrm{B}$ family of proteins (Salvesen and Abrams 2004; Hay and Guo 2006). In mammalian cells, however, it has been reported that zinc-induced caspase activation might rely on the inhibition of $\mathrm{NF} \kappa \mathrm{B}$ translocation to the nucleus (Ho et al. 2004) and in consequence, down-regulation of antiapoptotic proteins e.g., caspase inhibitors or antiapoptotic proteins from Bcl-2 family (Chang et al. 2006).

It is well known that caspase activity is directly regulated by inhibitor of apoptosis proteins IAPs (Salvesen and Abrams 2004). Domains called baculoviral IAP repeats (BIR), present in all noted IAPs, contain zinc atom which is required for their antiapoptotic activity (Shi 2007). It seems that IAPs may be potential targets of many PCD-inducers, including the excess of $\mathrm{Zn}$ ions in cytoplasm. It has been demonstrated by Ku et al. (2010) in mammalian cells that the exposure to zinc reduces the expression of survivin, a member of IAP family. Our study confirms that high concentration of $\mathrm{Zn}$ decreases the level of DIAP1 (Fig. 4), the fruit fly IAP1 protein that may activate Dronc and DrICEcaspases to begin apoptotic pathway.

\section{Conclusions}

Our results indicate for the first time that an excess of free zinc ions triggers PCD of haemocytes isolated from the third instar larvae of D. melanogaster. Zinc enters the cells and despite the stimulation of metallotionein B expression, increases significantly the pool of labile intracellular zinc ions. In consequence, metal ions decrease mitochondrial membrane potential and activate Dronc and DrICE caspases, associated with the intrinsic pathway of PCD. The enhanced activity of both caspases seems to be related to the low level of DIAP1 proteins observed in haemocytes exposed to high concentration of $\mathrm{Zn}^{2+}$. We observed that neither receptor-mediated $\mathrm{PCD}$ that utilized caspase Dredd nor calcium ions, do play the crucial role in PCD stimulation of the fruit fly immune cells exposed to high $\mathrm{Zn}$ concentrations. The mechanism of concentration-dependent $\mathrm{PCD}$ regulation by $\mathrm{Zn}$ ions is not fully understood yet and requires further studies. 
Acknowledgments This work was supported by the Polish Ministry of Science and Higher Education. Grant no N304 066 $32 / 2604$ to EP. Confocal microscope images have been obtained in Confocal Microscope Laboratory of the Department of Cell Biology and Imaging, Jagiellonian University.

Open Access This article is distributed under the terms of the Creative Commons Attribution License which permits any use, distribution, and reproduction in any medium, provided the original author(s) and the source are credited.

\section{References}

Abrams JM (1999) An emerging blueprint for apoptosis in Drosophila. Trends Cell Biol 9:435-440

Aiuchi T, Mihara S, Nakaya M, Masuda Y, Nakayo S, Nakaya K (1998) Zinc ions prevent processing of caspase-3 during apoptosis induced by geranylgeraniol in HL-60 cells. J Biochem 124:300-303

Atanesyan L, Günter V, Celniker SE, Georgiev O, Schaffner W (2011) Characterization of MtnE, the fifth metallothionein member in Drosophila. J Biol Inorg Chem 16:1047-1056

Balamurugan K, Egli D, Selvaraj A, Zhang B, Georgiev O, Schaffner W (2004) Metal-responsive transcription factor (MTF-1) and heavy metal stress response in Drosophila and mammalian cells: a functional comparison. Biol Chem 385:597-603

Beyersmann D, Haase H (2001) Function of zinc in signaling, proliferation and differentiation of mammalian cells. Biometals 14:331-341

Borowska J, Pyza E (2011) Effects of heavy metals on insects immunocompetent cells. J Insect Physiol 57:760-770

Chang K-L, Hung T-C, Hsieh B-S, Chen Y-H, Cheng H-L (2006) Zinc at pharmacologic concentrations affects cytokine expression and induces apoptosis of human peripheral blood mononuclear cells. Nutrition 22:465-474

Dorstyn L, Colussi PA, Quinn LM, Richardson H, Kumar S (1999) DRONC, an ecdyson-inducible Drosophila caspase. PNAS 96:4307-4312

Echalier G (1997) Drosophila cells in culture. Academic Press, New York

Egli D, Domènech J, Selvaraj A, Balamurugan K, Hua H, Capdevila M, Georgiev O, Schaffner W, Atrian S (2006) The four members of the Drosophila metallothionein family exhibit distinct overlapping roles in heavy metal homeostasis and detoxification. Genes Cells 11:647-658

Filipiak M, Bilska E, Tylko G, Pyza E (2010) Effects of zinc on programmed cell death of Musca domestica and Drosophila melanogaster. J Insect Physiol 56:383-390

Flieger D, Riethmüller G, Ziegler-Heitbrock HW (1989) $\mathrm{Zn}^{2+}$ inhibits both tumor necrosis factor-mediated DNA fragmentation and cytolysis. Int J Cancer 44:315-319

Fraker PJ, Telford WG (1997) A reappraisal of the role of zinc in life and death decisions of cells. PSEBM 215:229-236

Fraker PJ, King LE, Laakko T, Vollmer TL (2000) The dynamic link between the integrity of the immune system and zinc status. J Nutr 130:1399S-1406S
Gregori G, Ragheb K, Robinson JP (2004) Introduction to WinMDI 2.8 (J. Trotter 1993-1998) for the analysis of flow cytometry listmode data files. Purdue University Cytometry Laboratories, West Lafayette

Haase H, Hebel S, Engelhardt G, Rink L (2006) Flow cytometric measurement of labile zinc in peripheral blood mononuclear cells. Anal Biochem 352:222-230

Hay BA, Guo M (2006) Caspase-dependent cell death in Drosophila. Annu Rev Cell Dev Biol 22:623-650

Ho LH, Ruffin RE, Murgia Ch, Li L, Krilis SA, Zalewski PD (2004) Labile zinc and zinc transporter ZnT4 in mast cell granules: role in regulation of caspase activation and $\mathrm{NF} \kappa \mathrm{B}$ translocation. J Immunol 172:7750-7760

Hoffmann JA (1995) Innate immunity of insects. Curr Opin Immunol 7:4-10

Ibs K-H, Rink L (2003) Zinc-altered immune function. J Nutr 133:1452S-1456S

John E, Lascow TC, Buscher WJ, Pitt BR, Basse PH, Butterfield LH, Kalinski P, Lotze MT (2010) Zinc in innate and adaptive tumor immunity. J Transl Med 8:1-16

Neves I, Bertho L, Veloso VG, Nascimento DV, Campos-Mello DLA, Morgado MG (1998) Improvement of the lymphoproliferative immune response and apoptosis inhibition upon in vitro treatment with zinc on peripheral blood mononuclear cells (PBMC) from $\mathrm{HIV}^{+}$individuals. Clin Exp Immunol 111:264-268

Knoch ME, Harnett KA, Hara H, Kandler K, Aizenman E (2008) Microglia induce neurotoxicity via $\mathrm{Zn}^{2+}$ release and a $\mathrm{K}^{+}$ current surge. Glia 56:89-96

$\mathrm{Ku}$ JH, Seo SY, Kwak C, Kim HH (2010) The role of survivin and $\mathrm{Bcl}-2$ in zinc-induced apoptosis in prostate cancer cells. Urol Oncol. doi:10.1016/j.urolonc.2010.06.001

Lavine MD, Strand MR (2002) Insect hemocytes and their role in immunity. Insect Biochem Mol Biol 32:1295-1309

Lee SJ, Cho KS, Koh JY (2009) Oxidative injury triggers autophagy in astrocytes: the role of endogenous zinc. Glia 57:1351-1361

Lichten LA, Cousins RJ (2009) Mammalian zinc transporters: nutritional and physiologic regulation. Annu Rev Nutr 29:153-176

Livak KJ, Schmittgen TD (2001) Analysis of relative gene expression data using real-time quantitative PCR and $2^{-}$ $\Delta \Delta \mathrm{Ct}$ method. Methods 25:402-408

Mann JJ, Fraker PJ (2005) Zinc pyrithione induces apoptosis and increases expression of Bim. Apoptosis 10:369-379

Meister M (2004) Blood cells of Drosophila: cell lineages and role in host defense. Curr Opin Immunol 16:10-15

Perry DK, Smyth MJ, Stennicke HR, Salvesen GS, Duriez P, Poirier GG, Hannun YA (1997) Zinc is a potent inhibitor of the apoptotic protease, caspase-3. A novel target for zinc in the inhibition of apoptosis. $\mathrm{J}$ Biol Chem 30:18530-18533

Ribeiro C, Brehélin M (2006) Insect haemocytes: what type of cell is that? J Insect Physiol 52:417-429

Richardson H, Kumar S (2002) Death to flies: Drosophila as a model system to study programmed cell death. J Immunol Methods 265:21-38

Rink L, Gabriel P (2000) Zinc and immune system. Proc Nutr Soc 59:541-552

Rudolf E, Červinka M (2010) Zinc pyrithione induces cellular stress signaling and apoptosis in Hep-2 cervical tumor 
cells: the role of mitochondria and lysosomes. Biometals 23:339-354

Salvesen GS, Abrams JM (2004) Caspase activation-stepping on the gas or releasing the brakes? Lessons from humans and flies. Oncogene 23:2774-2784

Sensi S, Ton-That D, Sullivan P, Jonas E, Gee K, Kaczmarek L, Weiss J (2003) Modulation of mitochondrial function by endogenous $\mathrm{Zn}^{2+}$ pools. PNAS USA 100:6157-6162

Shi Y (2007) Caspase activation, inhibition, and reactivation: a mechanistic view. Protein Sci 13:1979-1987

Siegel RM (2006) Caspases at the crossroads of immune-cell life and death. Nat Rev Immunol 6:308-317

Song Z, Guan B, Bergman A, Nicholson DW, Thornberry NA, Peterson EP, Steller H (2000) Biochemical and genetic interactions between Drosophila caspases and the proapoptotic genes rpr, hid, and grim. Mol Cell Biol 20: 2907-2914

Szczerbina T, Banach Z, Tylko G, Pyza E (2008) Toxic effects of acrylamide on survival, development and haemocytes of Musca domestica. Food Chem Toxicol 46:2316-2319

Truong-Tran AQ, Ho LH, Chai F, Zalewski PD (2000) Cellular zinc fluxes and the regulation of apoptosis/gene-directed cell death. J Nutr 130:1459S-1466S
Tubek S (2007) Zinc supplementation and regulation of its homeostasis: advantages and threats. Biol Trace Elem Res 119:1-9

Wellinghausen N, Kirchner H, Rink L (1997) The immunobiology of zinc. Immunol Today 18:519-521

Yepiskoposyan H, Egli D, Fergestad T, Selvaraj A, Treiber C, Multhaup G, Georgiev O, Schaffner W (2006) Transcriptome response to heavy metal stress in Drosophila reveals a new zinc transporter that confers resistance to zinc. Nucleic Acids Res 34:4866-4877

Ze-peng Y, Guo-wei L, Hong-yu H, Yun-yu W, Yong-hui S (2005) Effect of different zinc sources and levels on inhibition of the apoptosis induced by glucocorticoid of thymocytes in vitro. Biol Trace Elem Res 105:215-227

Zhang B, Egli D, Georgiev O, Schaffner W (2001) The Drosophila homologue of mammalian zinc finger factor MTF1 activates transcription in response to heavy metals. Mol Cell Biol 21:4505-4514

Zhang Y, Wang H, Li J, Jimenez DJ, Levitan ES, Aizenman E, Rosenberg PA (2004) Peroxynitrite-induced neuronal apoptosis is mediated by intracellular zinc release and 12-lipoxygenase activation. J Neurosci 24:10616-10627 